\title{
On Convergence and Open Data: Challenges for Libraries, Archives and Museums
}

\author{
Eva Van Passel \\ iMinds-SMIT, Vrije Universiteit Brussel (1) \\ Pleinlaan 2, 1050 Brussels \\ Belgium \\ eva.van.passel@vub.ac.be
}

\author{
Olga Van Oost \\ (1) \& FARO. Flemish Interface Centre for Cultural Heritage \\ Priemstraat 51, 1000 Brussels \\ Belgium \\ olga.vanoost@faronet.be
}

\begin{abstract}
This paper addresses some of the challenges libraries, archives and museums face in the digital age, with a focus on organisational and strategic challenges in Flanders, Belgium. As we look at how cultural institutions approach digital access in a networked landscape, the concepts collaboration, convergence and aggregation are key. We first revisit the results of two Flemish research projects from the period 2009-2011. Additionally, we look at more recent policy approaches and implications. Moreover, departing from the ongoing project Europeana Inside, we widen the scope beyond Flanders to address the increasing commitment to open cultural data expected in Europe. We argue that this can be seen as a more recent challenge in the convergence sphere and we look at institutions' views with regards to open data in Flanders. In this way, the paper provides an update to the lessons learned from the projects. It indicates that, certainly in Flanders, high levels of cooperation, convergence and aggregation as well as commitment to open data are as yet still major challenges for many libraries, archives and museums.
\end{abstract}

Convergence. Open data. Europeana. Aggregation. Libraries. Archives. Museums. LAMs.

\section{INTRODUCTION}

Libraries, archives, museums and other heritage institutions face many important strategic choices in the digital age. Sustainable digital access to cultural heritage is envisaged in policies throughout Europe and beyond (see e.g. European Commission 2011a, The Council of the European Union 2006, UNESCO 2003). The matter is therefore also a growing point of attention for collaborative cross-border research and development projects and networks, within Europe most notably Europeana and its related projects. This landscape of digital access, requiring collaboration, aggregation and convergence, has a profound impact on individual institutions' positioning.

This paper will first revisit two research projects conducted in the period 2009-2011 that have focused on aspects of digital access to culture and heritage in Flanders, Belgium: a feasibility study for a cross-sector aggregator for metadata, commissioned by the Flemish Department of Culture, Youth, Sports and Media (Van Oost \& Coppens 2010); and Archipel, a large-scale collaborative project researching a network-centric approach to sustainable digital archives, more specifically a report on a strategic roadmap for sustainable digital archiving and distribution (Van
Passel 2011). Various research methods were used, including extensive literature studies and stakeholder consultations under the form of expert interviews and expert panel discussions, in order to gain insight in institutions' views on the preferred strategic road to digital access.

As we look at how cultural institutions in Flanders approach digital access in a networked landscape, the concepts of collaboration, convergence and aggregation will be key. We will map organisational, strategic and policy challenges museums, archives and libraries encounter on the road to digital access. We will first refer back to the main issues highlighted during the aforementioned research projects, but this paper will not be a mere project overview. Additionally we will also look at more recent policy approaches and announcements regarding digital access in Flanders. In this way, the paper will provide an update to the lessons learned from the projects.

Finally, we will also look at institutions' current perceptions of convergence and aggregation issues in a European context. Specifically, we will focus on views on participating to Europeana and the commitment to open data this entails, as well as on related opinions with regards to reuse of public sector information and how this impacts museums, libraries and archives. This part of the 
paper fits within the Best Practice Network Europeana Inside (2012) and its goal to remove barriers to participation in Europeana. As such, this paper will broaden the scope of the aforementioned research beyond the case study of Flanders, and will cover the wider EU policy sphere.

\section{CONVERGENCE AND AGGREGATION}

Previous research has indicated that collaboration, aggregation and convergence in the context of digital access to cultural content can be problematic from institutions' point of view. While our research focuses on Flanders, this is certainly the case beyond this context. This first section therefore starts with an international perspective. Convergence is seen as the endpoint of a continuum of varying degrees of collaboration between libraries, archives and museums:

\begin{abstract}
(...) a state in which collaboration around a specific function or idea has become so extensive, engrained and assumed that it is no longer recognized by others as a collaborative undertaking (Zorich, Waibel \& Erway 2008, p. 12).
\end{abstract}

A certain level of convergence is often described as desirable if the institutions are to fulfil their future missions in a digital era:

\begin{abstract}
It is clear that, if electronic sources of information are to be effectively managed for future access by historians and others, differences between libraries, archives, and museums will largely have to disappear and their different philosophies, functions, and techniques integrated in ways that are as yet unclear (Rayward 1998, p. 207).
\end{abstract}

The motivation of this trend lies largely in the goal of providing access to digital heritage that all these institutions share (Stuedahl 2007), stressed in policies throughout Europe and beyond as noted above.

However, we must not forget that cultural institutions have been in flux for several decades, influenced by larger societal trends. An overview of this context of transition is beyond the scope of this article, but the backdrop of these changes lies in societal changes and the transition to a late modern era. We refer to Van Oost (2009) for a detailed analysis of these evolutions. Suffice to stress that the context of convergence extends beyond the dawn of the digital age and is also related to the late modern questioning of previously unambiguous entities and institutions. Audience experiences, participation and interactivity are increasingly emphasised in discussions on the contemporary role of institutions such as museums (Falk \& Dierking 1992, Hein 2000, Stuedahl 2007,
Van Oost 2009). Digital technologies seem to be a natural ally in reaching goals of participatory access, but they are not the sole cause of the evolutions at hand. Many institutions see these times as challenging with regards to their missions and identities, regardless of the digital, which is sometimes merely seen as instrumental to reaching institutional goals. While digital technologies impact these transitions further, it is more accurate to see the digital as a catalyst rather than a cause of convergence (Drotner \& Laursen 2011). The question whether the trend is in fact new is rightly being asked (Given \& McTavish 2010).

Regardless of whether the convergence of institutions is new, acronyms such as LAMs (libraries, archives, museums; see e.g. Zorich, Waibel \& Erway 2008) and sometimes also GLAMs (including galleries; see e.g. Lim \& Liew 2011) have emerged in light of these evolutions. The concept of memory institutions is also used (see e.g. Dempsey 1999, Thomas 2004). These terms and acronyms are a symptom of the convergence trend. In practice, recent occurrences of convergence are often instigated from a policy level. In Norway for example the Norwegian Archive, Library and Museum Authority was founded in 2003 (Stuedahl 2007). Canada saw the merger of the National Archives of Canada with the National Library in 2004 (Given \& McTavish 2010) and Germany has seen the launch of a joint portal of archives, libraries and museums, BAM (Kirchhoff, Schweibenz \& Sieglerschmidt 2008).

It must be noted that these initiatives do not all imply that traditional institutions are being disbanded, but rather that collaborative digital memory institutions emerge that increase individual participating institutions' visibility (Dempsey 1999, Kirchhoff, Schweibenz \& Sieglerschmidt 2008). This is where the concept of aggregation comes into play. The feasibility study for a cross-sector aggregator for metadata this paper partially builds on (Van Oost \& Coppens 2010) lists a number of definitions, but the essence is combining content from multiple sources, in this case institutional, in one place. More importantly for the context of this paper, the study conceptualises aggregation for access, needed for large-scale initiatives such as Europeana, as an extensive form of collaboration. It can therefore be seen as one of the instances of convergence, a concept that describes a wider tendency.

While aggregator initiatives are manifold, LAMs, GLAMs or converged memory institutions have not yet become the norm in practice, nor are the concepts themselves commonplace. Collaboration between institutions is often still not straightforward, so by extension neither is convergence. Moreover, in the analogue world, the differences between the 
three institutional categories that make up LAMs remain especially significant. An interesting case on the struggles of convergence can be found in the Netherlands, where at the end of 2011, a merger between the Royal Library and the National Archive was announced. The communication explicitly referred to how the differences between both types of institutions have become much smaller in the digital age. However, this merger has temporarily been put on hold, as its benefits are now considered insufficiently proven (Zijlstra 2012). In sum, convergence of LAMs is an ongoing process with an uncertain outcome, and is often a practical struggle for memory institutions (Stuedahl 2007, Zorich, Waibel \& Erway 2008, Van Oost \& Coppens 2010).

\section{THE CASE OF FLANDERS, BELGIUM}

\subsection{Previous research}

The concepts of collaboration, convergence and aggregation have also played a major role in the two studies under review in this paper. Within Archipel, a strategic roadmap for sustainable digital archiving and distribution in Flanders was devised (Van Passel 2011). In contrast to more centralised initiatives elsewhere, the research project Archipel has focused on a network-centric approach to sustainable digital archiving and to providing access. The social-scientific aspects of the research have focused on creating solutions that are not only technically feasible, but also societally acceptable. To this end, qualitative stakeholder consultations under the form of an expert panel discussion were conducted, involving policymakers as well as representatives from the LAM field. These stakeholder consultations have revealed that recognising the importance of existing local initiatives is indispensable in order to create the required societal and sectoral support for largescale initiatives related to digital access (Van Passel 2011). This distinctly decentralised approach contrasts with a number of initiatives in neighbouring countries, most notably the Netherlands, where the difference has not gone unnoticed (Streefkerk 2011).

It is useful to very briefly sketch the policy context in Flanders to understand this differing approach. Digital culture or e-culture, a favoured term for digital cultural developments in Flanders, has only gained policy attention rather recently, with a publication that translates as "E-culture. Building Blocks for Practice and Policy" as an important milestone (De Wit \& Esmans 2006). As well as a milestone, the timeframe of the publication is also an indicator of how Flanders tends to lag behind its same-language neighbour the Netherlands in matters related to digital culture. The editors refer to a prior Dutch policy vision publication from 2003 (English edition: Netherlands Council for Culture (2004)) and explicitly mention that it is time for Flanders to take similar paths (De Wit \& Esmans 2006). In general, the international dimension to eculture is stressed throughout the publication, with explicit mentions of countries with a longer digital cultural policy tradition as sources of inspiration for Flanders. This publication has set the tone for a number of rather humble references to earlier adopters in the field of e-culture and digitisation: many policy documents have since included mentions of how Flanders lags behind (e.g. Schauvliege 2009, Schauvliege 2010).

The aforementioned feasibility study similarly stresses that digital culture has been on the policy agenda for less long in Flanders in comparison with e.g. France or the Netherlands. Moreover, it stresses that the tendency to recognise digitisation as more than an instrumental process, i.e. as a cultural transformation, is lacking (Van Oost \& Coppens 2010, pp. 31-33). In sum, even in 2010, a fully integrated policy view on digital culture had not yet emerged in Flanders. The study notes that this has an impact on the sustainability of e-culture initiatives such as joint aggregation in the digital age, not necessarily in a technical sense but certainly in terms of societal sustainability and the development of shared visions among institutions. In sum, while the feasibility of a cross-sector aggregator for metadata in Flanders was not necessarily problematic from a technical point of view, it was deemed to be more so from an organisational and policy point of view.

It could be argued that the delay in top-down approaches with regards to digital culture may help explain the emergence of bottom-up or highly local approaches. These in turn then motivate a more networked approach in later stages, acknowledging that already existing initiatives should be valorised. While aggregation and collaboration are key, initiatives do not tend to reach the level of full convergence, but rather take on a decentralised approach. While a comparison of Flemish and Dutch cultural policy is outside the scope of this paper, the aforementioned failed merger between the Royal Library and the National Archive (Zijlstra 2012) provides some indication of the fact that in the Netherlands, more centralised institutions are aimed for. It also indicates that even in this case, convergence can be problematic.

\subsection{Recent policies and implications}

While the research projects under review shed some light on collaboration, aggregation and convergence as challenges for LAMs, this paper wishes to go beyond their timeframe and look at more recent policies in order to detect any 
evolutions. In fact, it is clear that the lessons learned from the projects on the specific Flemish context and institutional perceptions have not gone unnoticed. More recent cultural policy documents have acknowledged the reluctance to convergence, by explicitly referring to the Archipel project and stating the principle of a decentralised Flemish digital archive structure for the implementation of the policy goal of sustainable digital archiving (Schauvliege 2010, Schauvliege 2012). As such, the project's premise of a networked archipelago of existing initiatives, respecting each institution's position and progress in terms of digitisation, has been reflected in policy.

A crucial stage in Flemish policy with regards to digital access to culture is the recent establishment of the Flemish Institute for Archiving and Distribution of Audiovisual Heritage (VIAA), for which funding was announced by the Ministers of Media and Culture at the end of 2012 (Lieten \& Schauvliege 2012). Audiovisual content is considered the most urgent to tackle, but the Institute will focus on a broad spectrum of digital heritage. While this sounds like a centralised approach, communications with regards to VIAA have been careful to stress the idea of collaboration, of a networked Flemish Digital Archive, of partnerships with many other experienced organisations (Santos 2013). So even in communications on seemingly more top-down driven initiatives such as VIAA, invalidating possible institutional resistance to highly centralised approaches has become an integral part of digital cultural policy in Flanders.

\section{OPEN DATA, AN ADDITIONAL CHALLENGE}

Strongly related to convergence and aggregation issues discussed above is the recent policy focus on open cultural data. While Archipel's infrastructure included a linked open data (LOD) server, and publishing metadata as LOD was researched in the feasibility study, organisational and strategic decisions with regards to open data were not prominently addressed in the research projects. Due to recent changes in the policy landscape, this issue has become more pressing.

As part of our goal to revisit the results and broaden the scope, this paper will therefore explore open data issues as an addition to the existing reports referred to. To this aim, we will not only address the case of Flanders, Belgium, but also place it in a wider European perspective in order to assess open data issues comparatively.

\subsection{Europeana Inside: reducing barriers}

As with the previous two projects referred to in this paper, a full project overview of Europeana Inside is not the goal of this paper; for this, we refer to the project website (Europeana Inside 2012). For the purposes of this paper, it is key to note that this CIP Best Practice Network is committed to reducing or removing barriers to participation in Europeana at several levels, i.e. organisational, legal, technical and financial. We will focus on open data as one of those potential organisational barriers. Participating content partners have shown a commitment to open data, as is required by Europeana and its Data Exchange Agreement (DEA, Europeana Professional 2012). Aside from evaluating technical aggregation issues, it is however worth considering to which extent this obligation of opening up metadata may be a stumbling block for other institutions. This is relevant, as the project wants to address barriers in the broader digital cultural ecosystem and not just for its own partners. It is also useful to consider whether signing the DEA has made institutions reconsider how much they are willing to share: the DEA clearly states that the data provider remains in control of how much metadata it wants to submit in addition to Europeana's minimum requirements. The next section elaborates on the idea of open data for LAMs as a new challenge in the increasingly converged landscape.

\subsection{Open data: new challenge, same issues?}

In terms of this paper, open cultural (meta)data can be redefined as a challenge strongly related to issues of collaboration, aggregation and convergence. Participation in Europeana in general is an illustration of collaboration, aggregation and convergence tendencies, and the recent implementation of the DEA has put open data in the spotlight. As a part of the larger convergence tendencies, commitment to open data is not always embraced fully. Indeed, within Europeana Inside, some project partners have expressed concern about sharing more metadata than strictly necessary. The Best Practice Network is not the only one addressing these issues. The DEA was not hailed without protest in the context of Linked Heritage either (Vassallo \& Piccininno 2012). By signing the DEA, providers in fact authorise Europeana to publish all metadata under the Creative Commons Universal Public Domain Dedication (CC0 1.0, Creative Commons 2009), and many museums do not agree with being required to allow commercial reuse under these terms (Vassallo \& Piccininno 2012).

While we have arrived at this issue from the point of view of Europeana Inside's goal of removing 
barriers to participating in Europeana, it is clear that the open data challenge for LAMs goes beyond the Europeana context. On a EU policy level, proposed amendments to the Directive 2003/98/EC on the reuse of public sector information (PSI Directive, European Commission 2011b) wish to include libraries, museums and archives in its remit. Even though the terms of the PSI Directive are not identical to those of Europeana's DEA with its CCO 1.0 use, the issues at hand are strongly related. As with the DEA, the proposed PSI amendments are controversial as well: a number of position papers exist contesting the inclusion of LAMs (SA\&S \& GCEA 2012, Weide 2012), and while Europeana itself is not against it, it does acknowledge that not all its network members agree (Europeana Foundation 2012).

To the authors' knowledge, there are no quantitative data available on the proportion of LAMs that are reluctant when it comes to open data, nor on the breakdown of those who are, geographically or by sector. The sources referred to may indicate that reluctance is higher in a museum context than it is for libraries and archives. One position paper is specifically from a museum background (Weide 2012), representing the Network of European Museum Organisations; another, while signed by a variety of institutions, points out the particular position of museums as stakeholder in the creative industry (SA\&S \& GCEA, 2012). The paper referred to in the Linked Heritage context (Vassallo \& Piccininno 2012) also explicitly refers to museum objections. However, data to prove this conclusively are not available, so conclusions cannot be drawn.

\subsection{Back to Flanders, Belgium}

Focusing again on the context of Flanders, Belgium, it is noteworthy that the highly critical position paper of the SA\&S and GCEA (2012) represents the view of a large number of Flemish and Brussels cultural heritage institutions. Europeana's PSI position paper also stresses that the voices from Belgium were strong and united (Europeana Foundation 2012). This indicates that open cultural data has not (yet) been embraced fully by the LAM sector in Flanders. Once again, this seems to be in contrast with the example of the Netherlands, where open cultural data advocacy is more common (Open Cultuur Data, 2011) and which counts several members of the OpenGLAM (n.d.) initiative.

We argue that this is perhaps unsurprising given the fact that in recent years, several research projects have demonstrated concerns from the Flemish LAM field about becoming involved in allembracing digital initiatives, including the projects discussed in this paper as well as earlier ones
(Beyl \& Van Passel 2011). As described in this paper, the Flemish context is one where many libraries, archives and museums have favoured approaches to be more networked and decentralised and where experts from the field as well as policy makers stress the need to valorise existing initiatives. While this is in itself not in contradiction with the idea of open data, it has been noted that this reluctance could potentially be traced back to more profound uncertainties institutions face about their role in a late modern society, with blurring boundaries and digital technologies catalysing these evolutions (Beyl \& Van Passel 2011). Institutional mentalities have a profound impact on LAMs' willingness to embrace certain challenges, and policy traditions and context play a major role in this (Van Passel \& Van Oost 2012). This could provide a potential explanation as to why many cultural heritage institutions in Flanders do not (yet) rejoice at the idea of opening up their data widely and without limitations.

\section{CONCLUSIONS AND FURTHER WORK}

High levels of cooperation, convergence and aggregation are as yet still a challenge for many libraries, archives and museums in Flanders, Belgium. This had already been demonstrated by the feasibility study for a cross-sector aggregator for metadata (Van Oost \& Coppens 2010) and the report on a strategic roadmap for sustainable digital archiving and distribution within Archipel (Van Passel 2011). However, this paper has broadened the scope of the aforementioned research projects in two ways: first, by bringing them up to date with the latest policy developments in Flanders; second, by placing them in the wider European context. These updates indicate that a proportion of LAMs are still very reluctant when it comes to certain aspects of convergence. Open data issues can be seen as a recent incarnation of the convergence challenge.

It is hard to pinpoint the exact reasons of this reluctance, though we have suggested that institutions' positions, mentalities and possible uncertainties about their roles and positions should not be ignored. This is also relevant for projects such as Europeana Inside: while it focuses on barriers in a general manner, it may benefit from the acknowledgment that these barriers can differ from context to context. There are for example some indications that a commitment to open data is much less an issue in the Netherlands than in Flanders. Aside from the geographical difference, we may also wonder whether museums are slightly more susceptible to this reluctance than libraries or archives. However, we repeat that this cannot be 
proven as long as no quantitative comparative data are available.

We therefore recommend more research into institutional positions with regards to convergence, aggregation, and, in the framework of Europeana Inside, specifically with regards to commitment to open data. Insights gained by such research can first be useful for Europeana to achieve a high quality standard of participation. Second, data that enable us to not only compare approaches in different EU member states, but also to map any differences between views of museums, libraries and archives, can be highly useful for evidencebased policy making. This would not only benefit Flanders, Belgium, but it might also impact the much wider EU policy agenda with regards to digital access to cultural heritage.

\section{ACKNOWLEDGEMENTS}

Europeana Inside is coordinated by Collections Trust and co-funded by the European Union under the ICT Policy Support Programme part of the Competitiveness and Innovation Framework Programme (grant agreement $n^{\circ}$ 297292). This publication only reflects the author's views. The European Union is not liable for any use that may be made of the information contained herein.

Archipel (October 2009 - December 2011) was a project funded by IWT (Agency for Innovation by Science and Technology, Flanders http://www.iwt.be/) in the PIM framework (Programme Innovative Media). A full list of project partners, including iMinds research centres, can be found on the project website http://www.archipelproject.be/.

The feasibility study for a cross-sector aggregator for metadata (Van Oost \& Coppens 2010) was commissioned by the Flemish Department of Culture, Youth, Sports and Media and conducted by iMinds-SMIT, Vrije Universiteit Brussel and iMinds-MMLab, Universiteit Gent.

\section{REFERENCES}

Beyl, J., and Van Passel, E. (2011) Hybrid Heritage in a Digital Society: Policy Expectations and Perceptions from the Field. In Bauwens, J., \& Nulens, G. (eds), Under Construction: Culture in a Network Society. SMIT cahier, Vol. 1. IBBT-SMIT, Vrije Universiteit Brussel, Brussels.

Creative Commons (2009) Creative Commons Universal Public Domain Dedication. http://creativecommons.org/publicdomain/zero/1.0/ (retrieved 3 April 2013).
De Wit, D., and Esmans, D. (eds) (2006) E-cultuur. Bouwstenen voor praktijk en beleid. Acco, Leuven.

Dempsey, L. (1999) Scientific, industrial, and cultural heritage. A shared approach: A research framework for digital libraries, museums and archives. Ariadne, 22, http://www. ariadne.ac.uk/issue22/dempsey/ (retrieved 5 February 2013).

Drotner, K., and Laursen, D. (2011) Introduction. MedieKultur, 27(50), pp. 1-6.

European Commission. (2011a) Commission Recommendation of 27.10.2011 on the Digitisation and Online Accessibility of Cultural Material and Digital Preservation. C(2011) 7579 final. European Commission, Brussels.

European Commission (2011b) Proposal for a Directive of the European Parliament and of the Council Amending Directive 2003/98/EC on re-use of public sector information. $\operatorname{COM(2011)~} 877$ final. European Commission, Brussels.

Europeana Foundation (2012) Position Paper: Proposed Amendments to PSI Directive. Europeana Foundation, The Hague.

Europeana Inside (2012) About Europeana Inside. http://www.europeana-inside.eu/about/index.html (retrieved 3 April 2013).

Europeana Professional (2012) Data Exchange Agreement.

http://pro.europeana.eu/web/guest/data-exchangeagreement (retrieved 3 April 2013).

Falk, H. J., and Dierking, L. D. (1992) The Museum Experience. Whalesback Books, Washington.

Given, L. M., and McTavish, L. (2010) What's Old Is New Again: The Reconvergence of Libraries, Archives, and Museums in the Digital Age. The Library Quarterly, 80(1), pp. 7-32

Hein, H. S. (2000) The Museum in Transition. A Philosophical Perspective. Smithsonian Institution Press, Washington / London.

Lieten, I., and Schauvliege, J. (2012) Persbericht 21 december 2012. Digitale archivering Vlaams erfgoed gaat van start. http://www.iminds.be/userfiles/files/persberichten/2 012/nl/20121221 Digitale archivering Vlaams erf goed gaat van start.pdf (retrieved 3 April 2013).

Kirchhoff, T., Schweibenz, W., and Sieglerschmidt, J. (2008) Archives, libraries, museums and the spell of ubiquitous knowledge. Archival Science, 8(4), pp. 251-266.

Lim, S., and Liew, C. L. (2011) Metadata quality and interoperability of GLAM digital images. Aslib Proceedings, 63(5), pp. 484-498.

Netherlands Council for Culture (2004) From ICT to E-culture. Advisory report on the digitalisation of 
culture and the implications for cultural policy. Netherlands Council for Culture, The Hague.

Open Cultuur Data (2011) http://www.opencultuurdata.nl/about/ (retrieved 3 April 2013).

OpenGLAM (n.d.) About us - OpenGLAM. http://openglam.org/about/ (retrieved 3 April 2013).

Rayward, W. B. (1998) Electronic Information and the Functional Integration of Libraries, Museums, and Archives. In Higgs E. (ed), History and Electronic Artefacts. Oxford University Press, Oxford.

SA\&S (Samenwerkingsverband Auteursrecht \& Samenleving), and GCEA (Gebruikersgroep Cultureel Erfgoed en Auteursrecht) (2012) Standpuntbepaling aangaande het Richtlijnvoorstel van 12 december 2011 tot amendering van Richtlijn 2003/98 van 17 november 2003 inzake het hergebruik van overheidsinformatie. http://www.auteursrechtensamenleving.be/ (retrieved 3 April 2013).

Santos, A. (2013) VIAA: saving our common history. http://www.iminds.be/en/blog/p/detail/viaasaving-our-common-history (retrieved 3 April 2013)

Schauvliege, J. (2009) Beleidsnota 2009-2014. Cultuur. Vlaamse Regering, Brussels.

Schauvliege, J. (2010) Beleidsbrief Cultuur 20102011. Stuk 758 (2010-2011) - Nr. 1, ingediend op 27 oktober 2010. Vlaams Parlement, Brussels.

Schauvliege, J. (2012) Beleidsbrief Cultuur. Beleidsprioriteiten 2012-2013. Stuk 1771 (20122013) - Nr. 1, ingediend op 22 oktober 2012. Vlaams Parlement, Brussels.

Streefkerk, M. (2011) Archipel of netwerk. http://www.den.nl/blog/bericht/3257 (retrieved 3 April 2012).

Stuedahl, D. (2007) Convergence, Museums and Digital Cultural Heritage. In Storsul, T., \& Stuedahl, D. (eds), Ambivalence Towards Convergence. Digitalization and Media Change. Nordicom, Gothenburg.

The Council of the European Union. (2006) Council Conclusions on the Digitisation and Online Accessibility of Cultural Material, and Digital Preservation (2006/C 297/01). Official Journal of the European Union, 7.12.2006, pp. C297/1C297/5.

Thomas, C. F. (2004) Memory institutions as digital publishers: a case study on standards and interoperability. OCLC Systems \& Services, 20(3), pp. $134-139$
UNESCO (2003) Charter on the Preservation of the Digital Heritage. UNESCO, Paris.

Van Oost, O. (2009) The Museum Question: a study of the art museum concept in modernity from a theoretical and historical perspective and a comparative analysis of museum policies in Flanders and the Netherlands and case studies. Vrije Universiteit Brussel, Brussels [unpublished PHD dissertation].

Van Oost, O., and Coppens, S. (2010) Haalbaarheidsstudie voor het opzetten van een Vlaamse horizontale, cross-sectorale metadata aggregator voor het digitaal cultureel erfgoed. Departement Cultuur, Jeugd, Sport en Media, Brussels.

Van Passel, E. (2011) Een strategische roadmap voor duurzame archivering en ontsluiting (Archipel WP2, Deeltaak 2.4). Consortium Archipel, Flanders.

Van Passel, E., and Van Oost, O. (2012) Cultural Memory Institutions in a Digital Age: The Practice of Best Practices and the Importance of Context. The VII International Conference on Cultural Policy Research (ICCPR 2012), Barcelona, Spain, 9-12 July 2012.

Vassallo, V., and Piccininno, M. (2012) Aggregating Content for Europeana: A Workflow to Support Content Providers. In Zaphiris, P., Buchanan, G., Rasmussen, E., \& Loizides, F. (eds), TPDL 2012. LNCS, vol. 7489, pp. 445-454. Springer, Heidelberg.

Weide, S. (2012) NEMO Statement on proposal of amendments to PSI directive (2003/98/EC). http://www. ne-mo.org (retrieved 3 April 2013).

Zijlstra, H. (2012). Brief van 26 oktober 2012 aan de Voorzitter van de Tweede Kamer der StatenGeneraal over bevriezen fusie Koninklijke Bibliotheek en Nationaal Archief. http://www.rijksoverheid.nl/documenten-enpublicaties/kamerstukken/2012/10/26/kamerbriefover-bevriezen-fusie-koninklijke-bibliotheek-ennationaal-archief.html (retrieved 5 February 2013).

Zorich, D. M., Waibel, G., and Erway, R. (2008) Beyond the Silos of the LAMs. Collaboration Among Libraries, Archives and Museums. OCLC Research, Dublin, $\mathrm{OH}$. 